\title{
MAPAS E HOLOGRAMAS COMO METÁFORAS PARA PENSAR OS DADOS SOBRE RELIGIÃO NO CENSO DO IBGE DE 2010: COMENTÁRIOS AO TEXTO NÚMEROS E NARRATIVAS, DE CLARA MAFRA
}

Carlos Alberto Steil ${ }^{1}$

O texto de Clara Mafra sobre a religião no censo demográfico do IBGE de 2010, ainda que se intitule "Números e narrativas", vai muito além deste binômio. Da sua contribuição às análises que vêm sendo realizadas pelos estudiosos que se ocupam da religião como uma questão social, gostaria de destacar dois aspectos que apresentam um aporte original e pouco abordado. O primeiro é a sua reflexão sobre os bastidores da elaboração das últimas versões do censo no que diz respeito à inclusão do tema da religião. A autora participou, como consultora externa do IBGE, deste processo, o que lhe permite nos oferecer um olhar que é ao mesmo tempo de fora e de dentro. $\mathrm{O}$ segundo aspecto diz respeito a uma tentativa de superar uma visão topográfica do campo religioso que tem predominado nas ciências sociais. Para além do tracejado de um mapa, que demarcaria as fronteiras entre denominaçóes e grupos religiosos num espaço social imaginado, Clara Mafra chama a atenção do leitor para uma outra ótica possível para se pensar a distribuição das religióes no campo religioso brasileiro. Como ela mesma propóe, trata-se de buscar as linhas de força, os ancoradouros e os fluxos que atravessam este campo, ao invés de focalizar as fronteiras religiosas que estariam situando cada igreja ou grupo religioso num território fechado, ainda que poroso e marcado por um trânsito intenso de fiéis, símbolos, ideias e objetos.

1 Doutor em Antropologia Social. Professor do Programa de Pós-Graduação em Antropologia Social da Universidade Federal do Rio Grande do Sul - UFRGS. E-mail: steil. carlosalberto@gmail.com

Debates do NER, Porto Alegre, Ano i4, N. 24, P. 29-37, JUl./DeZ. 2013 


\section{OS BASTIDORES DO CENSO}

Sobre os bastidores do censo, há que se considerar a importância de levar em conta as condições de produção dos dados dos recenseamentos e surveys para que se possa relativizar o peso dos números e desmistificar as porcentagens na elaboração dos argumentos e análises sociais sobre o campo religioso. Mesmo porque, como sugere Talal Asad (1993; 2003), a classificação de determinada prática como religiosa, assim como a definição de um elenco de religiôes a serem pesquisadas pelos censos, já se apresentam como um ato a serviço de certas configuraçôes dominantes de poder. Isto é, os censos partem sempre de um contexto pressuposto no qual agentes religiosos e sociais aparecem como atores em disputa pelos sentidos do próprio conceito legítimo de religião, num jogo de forças que envolve a sociedade como um todo. Assim, ao traçar um mapa do campo religioso, os números do censo, independentemente do contexto empírico, acabam reificando as concepções dominantes na sociedade e na cultura sobre o que definimos como religião e como secular, em grande medida partilhadas pelos cientistas da religião.

Nesse sentido, é preciso atender ao seu convite para que nos mantenhamos vigilantes sobre a definição de religião com que temos operado na história recente e sobre as impressões que a presença diferenciada das religiōes no espaço público e na mídia causam no próprio cientista. A produção de dados empíricos, assim como as metodologias de análise e de interpretação dos fatos sociais, está sempre imbricada nos contextos sociais e culturais nos quais os pesquisadores e os sujeitos da pesquisa estão envolvidos. Tanto a pergunta, inserida no questionário do censo, quanto a resposta fazem parte de uma narrativa e de uma teia de experiências, concepções e significados sobre o que é religião num determinado momento histórico e social. Talvez se pudesse, aqui, fazer referência ao paradigma da corporeidade, na medida em que este reivindica a indissociabilidade entre a experiência, vivida como habitus que se impõem aos sujeitos como um sistema de predisposiçōes corpóreas, e a percepção dos fatos (Csordas, 2008; Carvalho; Steil, 2008). Ou seja, ainda que os números e os dados empíricos possuam objetividade e autonomia, construídas por meio de procedimentos metodológicos rigorosos

Debates do NER, Porto Alegre, ANo I4, N. 24, P. 29-37, JUl./DeZ. 2013 
aplicados na coleta das informações, a dimensão subjetiva da emoção, da intuição, do movimento sempre transbordam da experiência corpórea para a análise e a interpretação.

Por outro lado, há outro risco, recorrente na análise e interpretação do fato religioso, que é o de deixar-se impactar pelo novo que emerge como um fator disruptor em relação a uma situação estabelecida, apontando para uma configuração futura da sociedade que já estaria dada no presente. Nesse sentido, gostaríamos de chamar a atenção para os efeitos que o crescimento de dois grupos recenseados - os pentecostais e os "sem religião" - têm produzido na análise da presença destes grupos na sociedade brasileira. Ou seja, o aumento das porcentagens referentes a estas duas categorias classificatórias do censo estaria, na perspectiva da autora, produzindo uma certa distorção do olhar sobre as transformaçóes do campo religioso brasileiro. Assim, a recorrência e aceleração relativas ao crescimento dos pentecostais nos últimos censos têm levado alguns cientistas sociais e agentes religiosos a extrapolarem o âmbito empírico e a concluírem que o Brasil estaria caminhando a passos largos para se tornar uma sociedade protestante. Da mesma forma, um número expressivo de cientistas sociais, imbuídos das teorias weberianas, vem interpretando o crescimento dos "sem religião" como a confirmação de um processo histórico, em curso, de secularização e desencantamento do mundo, que se imporia às sociedades ocidentais como um destino inexorável. Na contramão destas duas tendências interpretativas, o texto de Clara Mafra aponta para uma série de especificidades que relativizam e tornam insustentáveis estas extrapolações empíricas. Ao fazer-se uma análise mais detalhada do censo, na qual os dados sobre religião são cruzados com outros dados, como renda, sexo, localidade e faixa etária, por exemplo, observa-se uma realidade complexa que não permite organizar os dados de forma linear numa direção histórica teleológica.

Em alguma medida, poderíamos associar esta perspectiva teleológica, presente na análise dos dados do censo, ao uso do conceito de religião como categoria analítica. Uma possibilidade de questionamento a esta teleologia poderia ser buscada na crítica pós-colonial. Os pós-coloniais têm procurado mostrar o quanto o conceito ocidental de religião, forjado no contexto 
das ciências sociais, exclui as experiências e crenças que se situam fora do campo de visão de uma modernidade que, a partir de um centro imaginado, pretende anular e encompassar as diferenças que estariam sendo produzidas a partir das margens. Como tem assinalado o historiador indiano Dipesh Chakrabarty, os conceitos de "história", "religião" e "política", por mais abrangentes que possam parecer, têm a Europa como o sujeito soberano, teórico, de todas as histórias, incluindo as que chamamos de "indianas", "chinesas" e "latinas" (Chakrabarty, 1997). Em certo sentido, explicitar essa relação de dependência do conceito de religião com o qual operamos nas ciências sociais permite colocar-se numa outra perspectiva e observar outras dimensóes da realidade espaço-temporal que emerge dos dados do censo.

\section{A METÁFORA DO HOLOGRAMA PARA INTERPRETAR OS DADOS}

O segundo aspecto, apresentado por Clara Mafra, e que passamos a comentar aqui, tem fortes incidências sobre a questão dos múltiplos pertencimentos religiosos que aparecem frequentemente nas etnografias e pesquisas qualitativas, mas que ficam escondidos nos dados quantitativos dos censos. A proposta da autora de substituir o mapa pelo holograma como metáfora para se pensar o campo religioso, em alguma medida, pode nos ajudar a compreender as possibilidades de a mesma pessoa frequentar, ao mesmo tempo, duas religióes, assim como os trânsitos constantes de idas e vindas que se observam na dinâmica religiosa no país. ${ }^{2}$ Diferentemente do mapa, que nos apresenta as religiōes como unidades compartimentadas numa topografia plana, o holograma nos dá a informação do todo e a posição relativa de cada parte, permitindo reconstruir uma imagem com informação tridimensional. Assim, cada religião reproduz em seu interior a dinâmica do religioso corporeificado no contexto cultural e social, que poderá ser visto

2 O nome Holografia vem do grego holos (todo, inteiro) e graphos (sinal, escrita), pois é um método de registro "integral” da informação com relevo e profundidade. Disponível em: <http://pt.wikipedia.org/wiki/Holografia>. Acesso em: 29 maio 2013.

Debates do NER, Porto Alegre, ANo I4, N. 24, P. 29-37, JUl./DEZ. 2013 
na íntegra, ainda que a partir do ângulo restrito dos dados numéricos levantados no censo. Os números de que dispomos, portanto, funcionam como uma fresta que abrimos numa parede, atrás da qual existe uma paisagem a ser observada. Ainda que estreita, a fresta nos permite ver toda a paisagem, por diferentes ângulos, dependendo da posição que tomamos.

Enfim, o censo também não nos oferece uma fotografia das religiões no país, mas a possibilidade de um olhar sobre as aspirações coletivas e as práticas sociais que produzem a diversidade do campo religioso brasileiro, que se revela por meio das categorias utilizadas pelo censo para classificar e organizar as diferenças. Mesmo porque, para mantermos a metáfora do holograma, poderíamos dizer que, ao contrário da fotografia, que apenas permite registrar as diferentes intensidades de luz provenientes da cena fotografada, os hologramas registram também a fase da radiação luminosa proveniente dos objetos que lhe deram origem. Assim, ao olhar os hologramas de diferentes ângulos, o observador verá os objetos de diferentes perspectivas. ${ }^{3} \mathrm{Na}$ transposição desta metáfora para o campo da interpretação do que os números dos censos nos permitem ver, podemos afirmar que estes nos permitem observar linhas e fluxos de experiências que se entrelaçam para configurarem, num movimento contínuo, a multiplicidade de formas e instituições que compóem a paisagem religiosa brasileira. Ou seja, ao propor substituir a metáfora do mapa ou da fotografia pela do holograma, Clara Mafra nos convida a tomar os dados como informações que, ao invés de fixar uma imagem do campo religioso, permitem, por meio de seus cruzamentos e do confronto com outros dados (obtidos por meio de etnografias e de pesquisas qualitativas), perceber sua mobilidade e sua diversidade, que não se deixa capturar pelas categorias de análise previamente definidas na elaboração dos questionários do censo, que pretendem construir um mapa religioso de fronteiras definidas.

A metáfora do holograma nos aproxima, ainda, da noção de ideoscapes (paisagens ideológicas), proposta por Appadurai para imaginar a heterogenei-

3 A comparação entre a fotografia e o holograma retiramos do site <http://www.cienciaviva. pt/projectos/pulsar/hologramas.asp>. Acesso em: 29 maio 2013.

Debates do NER, Porto Alegre, Ano I4, N. 24, P. 29-37, JUl./Dez. 2013 
zação dos espaços sociais. Como afirma o autor, o sufixo scapes permite-nos apontar para as formas (shapes) fluidas e irregulares das paisagens (landscapes) que caracterizam os contextos globais (Appadurai, 2005, p. 33). Este recurso linguístico, utilizado por Appadurai, sugere que é preciso abrir mão da busca por limites claros ou relações objetivamente dadas entre os grupos religiosos. Mesmo porque, na perspectiva dos atores individuais, a paisagem religiosa se apresenta como um campo aberto de possibilidades a ser explorado, e não um terreno demarcado por fronteiras proibidas de serem transpostas. Em alguma medida, poderíamos dizer que a mudança mais decisiva é a do indivíduo que se constitui, enquanto tal, atravessado por linhas e fluxos do mundo em movimento em que vivemos. Com isto, não queremos afirmar que não existam comunidades ou redes de pertencimentos religiosos relativamente estáveis, mas, sim, que a urdidura destas estabilidades é continuamente atravessada pela trama do movimento da vida pessoal e coletiva. Deste modo, as pessoas e os grupos defrontam-se quotidianamente com o fato de ter que imaginar ancoradouros estáveis para suas identidades provisórias e suas fantasias de proteção, asseguradas por fronteiras intransponíveis.

É neste movimento global que emergem as religiôes, ainda que vistas a partir de dados nacionais. Mesmo porque, como observa Paulo Fernando C. de Andrade num outro comentário publicado como parte deste debate, o campo religioso brasileiro precisa ser observado à luz de configurações que a religião e a secularização adquirem em outros países ou continentes, como os Estados Unidos e a Europa, para poder ser compreendido na sua particularidade, diferença e semelhança. Esta mesma tentativa de transcender os limites dos contextos nacionais para interpretar a dinâmica religiosa será proposta por Alejandro Frigerio, ao operar com o conceito de campo religioso transnacional (Frigerio, 2013; Csordas, 2009; De la Torre; Zuñiga, 2012; Oro, 1999). E, aqui, não se trata apenas de descrever os processos de transnacionalização das religiões, que transpõem fronteiras nacionais em múltiplos sentidos: sul, norte, leste, oeste; mas de chamar a atenção para o contexto da globalização como um outro locus da imaginação religiosa que, sem abandonar as referências às comunidades nacionais, incorpora configurações que as transcendem. Nesse sentido, o local não se opõe ao

Debates do NER, Porto Alegre, ANo I4, N. 24, P. 29-37, JUl./DeZ. 2013 
global como planos opostos e excludentes, mas ambos aparecem como dimensões do religioso, que se institui na tensão contínua e criativa entre estes dois planos. Ou seja, a transnacionalização religiosa não é um fato externo às religiōes, mas, ao contrário, é constitutiva das suas existências e identidades. Ou seja, ao se tomar como horizonte interpretativo o campo religioso transnacional, nos damos conta de que todas as religiōes fazem parte de uma paisagem comum, que engloba as diferenças nacionais ou locais, sem anulá-las ou torná-las homogêneas.

\section{CONSIDERAÇÕES FINAIS}

Caberia, ainda, uma pergunta de teor político: a quem interessa manter a metáfora do mapa na leitura dos dados do censo? Sem pretender ser exaustivo e explorar uma extensa gama de sujeitos e grupos que possam estar interessados em organizar e dispor os dados do censo como um mapa das religióes no Brasil, gostaria de destacar três grupos. O primeiro é o das lideranças das religiões cristãs hegemônicas, para as quais a metáfora do mapa se alinha com a ideia de conquista e guerra santa pela ocupação de territórios imaginados. O segundo é o dos intelectuais que se veem imbuídos da missão de descrever e esquadrinhar o campo religioso brasileiro como um espaço de disputas ideológicas. O terceiro é o dos políticos que precisam identificar os seus interlocutores no campo religioso para qualificá-los como possíveis aliados nos pleitos eleitorais e no Congresso.

Por outro lado, convém perguntar a quem pode não interessar o mapa das religiōes. Primeiramente, pode não interessar às religiões de matriz africana, na medida em que estas tendem a ficar subsumidas pela identidade católica abrangente que as engloba. É recorrente que os adeptos das religióes afro-brasileiras, quando interrogados pelos recenseadores, se declarem católicos, uma vez que foram batizados nesta religião ou assim se consideram por tradição familiar. Soma-se a isto o fato de a concepção de religião na tradição afro-brasileira ter sido forjada num outro ambiente histórico, diferente daquele das religiões cristãs, que incorporaram o mapa como parte de sua estratégia de expansão desde as Cruzadas e a conquista 
do Novo Mundo até os dias de hoje, na guerra dos evangélicos contra as religiōes de matriz africana.

Por fim, pode não interessar aos adeptos da Nova Era, uma vez que estes procuram se situar fora da religião, na medida em que esta categoria designa instituições específicas, forjadas a partir da perspectiva histórica ocidental da transcendência divina. Assim, a concepção de religião com que operamos na sociedade brasileira, onde quase $87 \%$ da população se declara cristã, traz as marcas políticas das divisões e dos cismas que ocorreram na organização terrena do cristianismo, assim como o conteúdo epistemológico do conceito, forjado neste ambiente histórico ao longo dos últimos dois mil anos. Ou seja, a religião, como um demarcador de fronteiras políticas e de identidades culturais, impregna inexoravelmente o conceito que utilizamos em nossas análises e interpretações dos dados do censo. A evitação do uso desta categoria pelos seguidores da Nova Era, que preferem nominar suas experiências e práticas rituais como espiritualidades, poderia ser tomada como um convite aos cientistas sociais a colocar em suspeição o conceito de religião como algo natural ou universal.

\section{REFERENNCIAS}

APPADURAI, Arjun. Modernity at Large. Minneapolis: University of Minnesota Press, 2005.

ASAD, Talal. Genealogies of religion: Disciplines and Reasons of Power in Islam and Christianity. Baltimore: Johns Hopkins University Press, 1993.

. Formations of the Secular: Christianity, Islam, Modernity. Stanford: Stanford University Press, 2003.

CARVALHO, Isabel Cristina Moura; STEIL, Carlos Alberto. A sacralização da natureza e a "naturalização" do sagrado: aportes teóricos para a compreensão dos entrecruzamentos entre saúde, ecologia e espiritualidade. Ambiente e Sociedade, Campinas, v. 11, p. 289-305, 2008. 
CHAKRABARTY, Dipesh. Postcoloniality and the artifice of history: who speaks for "Indian" pasts? In: MONGIA, P. (Org.). Contemporary Postcolonial Theory: A Reader. Nova Delhi: Oxford University Press, p. 223-247, 1997.

CSORDAS, Thomas J. Corpol significado/ cura. Porto Alegre: Ed. da UFRGS, 2008.

(Ed.) Transnational Transcendence: Essays on Religion and Globalization. Berkeley: University of California Press, 2009.

DE LA TORRE, Renée; ZÚNIGA, Cristina Gutiérrez. Transnacionalización de las danzas aztecas y relocalización de las fronteras (México/Estados Unidos). Debates do NER, Porto Alegre, n. 21, p. 11-48, jan./jul. 2012.

FRIGERIO, Alejandro. A transnacionalização como fluxo religioso na fronteira e como campo social: Umbanda e Batuque na Argentina. Debates do NER, Porto Alegre, n. 23, jan./jul. 2013. No prelo.

ORO, Ari. Axé Mercosul: As religiōes afro-brasileiras nos países do Prata. Petrópolis: Vozes, 1999. 